\title{
Predicting early left ventricular dysfunction after mitral valve reconstruction: The effect of atrial fibrillation and pulmonary hypertension
}

\author{
Robin Varghese, MD, MS, FRCSC, Shinobu Itagaki, MD, Anelechi C. Anyanwu, MD, MSc, FRCS, \\ Federico Milla, MD, and David H. Adams, MD
}

\begin{abstract}
Objective: The preoperative ejection fraction (EF) and left ventricular (LV) end-systolic dimension are known predictors of postoperative LV dysfunction after mitral valve repair. We investigated the effect of a preoperative history of atrial fibrillation and moderate pulmonary hypertension (defined as pulmonary artery systolic pressure $>50 \mathrm{~mm} \mathrm{Hg}$ ) on early postoperative LV dysfunction.
\end{abstract}

\begin{abstract}
Methods: From 2003 to 2010, 632 patients who had undergone successful mitral valve repair surgery for degenerative disease were included in the present study. The preoperative and postoperative echocardiographic data and postoperative outcomes were collected retrospectively. We analyzed the demographic, hemodynamic, and echocardiographic parameters to assess the predictors of early postoperative LV dysfunction, defined as an LVEF $<50 \%$.
\end{abstract}

Results: The mean age of the cohort was $57 \pm 13$ years. All patients had less than mild mitral regurgitation on postoperative echocardiography. After mitral valve repair, a significant decrease in the LVEF $60 \% \pm 8 \%$ to $54 \% \pm 9 \%$ ), LV end-systolic diameter $(36 \pm 7 \mathrm{~mm}$ to $33 \pm 7 \mathrm{~mm}$ ), and $\mathrm{LV}$ end-diastolic dimension (56 $\pm 8 \mathrm{~mm}$ to $48 \pm 7 \mathrm{~mm}$ ) was observed at early postoperative echocardiography $(P<.001)$. On multivariate regression analysis, preoperative atrial fibrillation, pulmonary hypertension, and LV end-systolic dimension were independent predictors of the postoperative $\operatorname{LVEF}(P=.035$ and $P<.001$, respectively). Preoperative atrial fibrillation (odds ratio, 1.97; 95\% confidence interval, 1.28-3.02; $P=.002$ ) and pulmonary artery systolic pressure $>50 \mathrm{~mm} \mathrm{Hg}$ (odds ratio, $1.82 ; 95 \%$ confidence interval, 1.11-2.97; $P=.017$ ) increased the risk of postoperative LV dysfunction by almost twofold.

Conclusions: In addition to the established predictors of postoperative LV dysfunction, the presence of preoperative pulmonary hypertension and a history of atrial fibrillation in patients undergoing mitral valve repair surgery increased the risk of early postoperative LV dysfunction by almost twofold. (J Thorac Cardiovasc Surg $2014 ; 148: 422-7)$

Mitral valve repair is the recommended treatment for patients with severe degenerative mitral valve disease. Despite having a preoperative preserved ejection fraction (EF), a number of patients will develop early left ventricular (LV) dysfunction after valve reconstruction. A number of studies have examined the echocardiographic predictors of LV dysfunction after valve replacement. ${ }^{1}$ However, some have examined this question in a mixed cohort of valve repair and valve replacement, ${ }^{2,3}$ and others have examined a mixed cohort of mitral valve disease

From the Department of Cardiothoracic Surgery, Icahn School of Medicine, Mount Sinai Medical Center, New York, NY.

Disclosures: Dr Adams is a consultant and inventor with Edwards Lifesciences. All other authors have nothing to disclose with regard to commercial support.

Received for publication May 27, 2013; revisions received Aug 2, 2013; accepted for publication Aug 22, 2013; available ahead of print Oct 30, 2013.

Address for reprints: Robin Varghese, MD, MS, FRCSC, Department of Cardiothoracic Surgery, Icahn School of Medicine, Mount Sinai Medical Center, 1190 Fifth Ave, Box 1028, New York, NY 10029 (E-mail: robin.varghese@ mountsinai.org)

0022-5223/\$36.00

Copyright (c) 2014 by The American Association for Thoracic Surgery

http://dx.doi.org/10.1016/j.jtcvs.2013.08.073 (degenerative, ischemic, and rheumatic). ${ }^{4}$ None have thoroughly examined the nonechocardiographic predictors of early postoperative LV dysfunction. Furthermore, whether early postoperative LV dysfunction after mitral valve reconstruction affects morbidity and mortality has not been examined.

In the present large series, we sought to examine the echocardiographic and nonechocardiographic predictors of early postoperative LV dysfunction after mitral valve repair for degenerative valve disease and its effects on surgical outcomes.

\section{METHODS \\ Study Population}

From June 2003 to December 2010, we retrospectively analyzed the data from 646 consecutive patients who underwent mitral valve surgery for degenerative mitral valve regurgitation by a single surgical team. Patients were excluded from the present study if they had undergone mitral valve replacement (1 patient) or had not undergone a complete predischarge echocardiogram (13 patients). Patients with concomitant tricuspid valve repair or coronary artery bypass grafting for incidental coronary disease found during preoperative catheterization were included 


\section{Abbreviations and Acronyms \\ $\mathrm{AF} \quad=$ atrial fibrillation \\ $\mathrm{EF} \quad=$ ejection fraction \\ $\mathrm{LV}=$ left ventricular \\ $\mathrm{LVEF}=$ left ventricular ejection fraction \\ PHT $=$ pulmonary hypertension}

in the present study. After the exclusions, 632 patients were included in the present analysis.

The Mount Sinai School of Medicine institutional review board approved the present research protocol.

The patients underwent a variety of techniques in repairing the mitral valve using a lesion-specific approach, as described previously. ${ }^{5,6}$ These techniques included quadrangular or triangular resection, leaflet sliding plasty, neochordal replacement, and commissuroplasty. Most patients received a complete annuloplasty ring; a small percentage received an incomplete annuloplasty ring. Tricuspid valve repair was undertaken if more than mild regurgitation or annular dilatation was present. Complete left sided or biatrial ablation was undertaken for all patients in persistent or permanent atrial fibrillation (AF).

During valve repair, myocardial protection was maintained using an induction dose of antegrade blood cardioplegia, with maintenance cardioplegia given mostly in a retrograde manner by way of a catheter in the coronary sinus. Cold blood cardioplegia was administered at $4{ }^{\circ} \mathrm{C}$ and consisted of a 4:1 ratio of blood to cardioplegia. The doses were administered approximately every 20 to 25 minutes. Before removal of the crossclamp, a dose of warm blood was administered through the retrograde catheter.

\section{Echocardiographic Parameters}

All patients had a preoperative transthoracic echocardiogram documenting severe mitral valve regurgitation. The degree of regurgitation was measured using a variety of techniques according to the guidelines of the American Society of Echocardiography. If doubt was present regarding the degree of mitral valve regurgitation on an echocardiogram from an outside institution, the echocardiogram was repeated at our hospital using proximal isovelocity surface area (effective regurgitant orifice area, effective regurgitant volume) and qualitative measurements such as reversal of flow in the pulmonary veins to assess mitral regurgitation. Transthoracic echocardiograms were performed in all patients after valve repair and before discharge from the hospital. The mean interval to echocardiography was 4.1 days. Postoperative LV dysfunction was defined as an $\mathrm{LVEF}<50 \%$. Other echocardiographic parameters such as the LV end-systolic diameter (LVESD), LV end-diastolic diameter (LVEDD), and left atrial diameter were also measured using the American Society of Echocardiography guidelines. Preoperative pulmonary artery systolic pressures were obtained from preoperative catheterization if available and, if not, by echocardiography using the simplified Bernoulli's equation [pulmonary artery systolic pressure $=4 \times(\text { peak tricuspid regurgitant velocity })^{2}+$ mean right atrial pressure]. Pulmonary hypertension (PHT) was defined using the American Heart Association/American College of Cardiology guideline of $50 \mathrm{~mm} \mathrm{Hg}$. $\mathrm{AF}$ was defined as permanent, persistent, and paroxysmal AF. All patients with permanent or persistent AF underwent ablation. All but 1 patient with paroxysmal AF underwent ablation. That patient had a history of 1 brief episode of paroxysmal AF and did not undergo ablation.

\section{Statistical Analysis}

Continuous variables are presented as the mean \pm standard deviation, if normally distributed, and the median and interquartile range, if not normally distributed. Categorical variables are presented as proportions and absolute numbers. For continuous variables, the normality test was performed using the combination of the Kolmogorov-Smirnov test and a visual assessment of the histograms. The differences between the 2 groups were detected using the chi-square test or Fisher's exact test for categorical variables and unpaired and paired Student $t$ tests or the Mann-Whitney $U$ test for continuous variables. Logistic and linear regression analyses were performed to identify the univariate and multivariate predictors of postoperative LV dysfunction and LVEF, respectively. Variables with $P<.25$ on univariate analysis were included in the final multivariate model. In logistic regression analysis, the model fit and predictive power were validated using the Hosmer-Lemeshow goodness-of-fit test and c-statistic. Before multivariate analysis, a correlation analysis between each variable was performed (Pearson or Spearman, as appropriate) to ensure no violation of the assumption of multicollinearity (cutoff correlation coefficient $<0.7$ ). The results are presented as odds ratios, with the corresponding $95 \%$ confidence intervals. $P<.05$ was considered statistically significant. All $P$ values are the results of 2 -tailed tests. The statistical analysis was performed using IBM SPSS Statistics for Windows, version 20.0 (SPSS, Inc, IBM Corp, Armonk, NY).

\section{RESULTS}

The baseline characteristics of the patients are listed in Table 1. Of the 646 patients, $242(38.3 \%)$ developed postoperative LV dysfunction. We observed that $68 \%$ of the patients in the series had a preoperative LVEF $>60 \%$ and $85.3 \%$ of patients had a preoperative LVEF $>50 \%$. On average, the patients who developed LV dysfunction were 2.7 years older. More than one half of the patients $(57.9 \%)$ in the series were symptomatic. The preoperative comorbidities were otherwise similar in both groups. The mean preoperative LVEF was slightly lower in the patients who developed postoperative LV dysfunction compared with those who did not $(59.3 \%$ vs $61.5 \%)$. The patients who developed postoperative LV dysfunction were more likely to have a dilated ventricle, PHT, and AF. The etiology of the degenerative disease was not different, and the repair techniques used were similar in both groups (Table 2). Barlow's disease was evident in 339 patients $(53.6 \%)$, and posterior leaflet prolapse was the most common lesion noted (475 patients; $75.2 \%)$. Tricuspid annuloplasty was undertaken in 413 patients $(65.3 \%)$.

The mean cardiopulmonary bypass times and crossclamp times were not significantly different between the 2 groups (Table 2).

Figure 1 illustrates the preoperative and postoperative cardiac chamber sizes in the entire series. The mean postoperative LVEF changed in the entire cohort by a mean of $-7.3 \% \pm 10.8 \%$. After valve repair, a significant decrease was seen in the LVESD, LVEDD, and left atrial diameter.

Tables 3 and 4 list the independent predictors of postoperative LV dysfunction after mitral valve repair, including LVESD, preoperative $\mathrm{AF}$, and preoperative PHT. The preoperative LVEF showed a trend toward predicting postoperative LV dysfunction but the difference was not statistically significant. We observed that in patients with a preoperative LVEF of $<60 \%, 34.2 \%$ 
TABLE 1. Baseline demographic data

\begin{tabular}{|c|c|c|c|c|}
\hline \multirow[b]{2}{*}{ Variable } & \multirow[b]{2}{*}{ All patients $(n=632)$} & \multicolumn{3}{|c|}{ Postoperative LV dysfunction } \\
\hline & & No $(n=390)$ & Yes $(n=242)$ & $P$ value \\
\hline \multicolumn{5}{|l|}{ Demographics and comorbidity } \\
\hline Age $(y)$ & $57.0 \pm 13.2$ & $56.0 \pm 13.1$ & $58.7 \pm 8.1$ & $<.001$ \\
\hline Female gender & $229(36.2)$ & $148(37.9)$ & $81(33.5)$ & .255 \\
\hline Body surface area $\left(\mathrm{m}^{2}\right)$ & $1.90 \pm 0.25$ & $1.89 \pm 0.24$ & $1.92 \pm 0.25$ & .193 \\
\hline Hypertension & $290(45.9)$ & $179(45.9)$ & $111(45.9)$ & .994 \\
\hline Hypercholesterolemia & $163(25.8)$ & 105 (26.9) & $58(24.0)$ & .409 \\
\hline Diabetes mellitus & $20(3.2)$ & $8(2.1)$ & $12(5.0)$ & .042 \\
\hline Coronary artery disease & $74(11.7)$ & $38(9.7)$ & $36(14.9)$ & .051 \\
\hline Obstructive lung disease & $19(2.9)$ & $1(0.8)$ & $4(2.9)$ & .234 \\
\hline Peripheral vascular disease & $7(1.1)$ & $6(1.5)$ & $1(0.4)$ & .288 \\
\hline Renal failure & $2(0.3)$ & $2(0.5)$ & $0(0)$ & .260 \\
\hline Cerebrovascular accident & $14(2.2)$ & $6(1.8)$ & $8(3.3)$ & .225 \\
\hline Symptomatic & $366(57.9)$ & $228(58.5)$ & $138(57.0)$ & .722 \\
\hline \multicolumn{5}{|c|}{ Preoperative echocardiographic parameters } \\
\hline $\operatorname{LVEF}(\%)$ & $60.7 \pm 7.5$ & $61.5 \pm 6.7$ & $59.3 \pm 8.4$ & $<.001$ \\
\hline $\mathrm{LVEF}<50 \%$ & $65(10.3)$ & $28(7.2)$ & $37(15.3)$ & .001 \\
\hline $\operatorname{LVESD}(\mathrm{mm})$ & $35.8 \pm 6.8$ & $34.6 \pm 6.2$ & $37.8 \pm 7.3$ & $<.001$ \\
\hline LVESD > $40 \mathrm{~mm}$ & $159(25.2)$ & $74(19.0)$ & $85(35.1)$ & $<.001$ \\
\hline PA systolic pressure $(\mathrm{mm} \mathrm{Hg})$ & $34.6 \pm 13.3$ & $32.3 \pm 11.6$ & $38.0 \pm 14.5$ & $<.001$ \\
\hline LVEDD (mm) & $56.0 \pm 7.9$ & $54.9 \pm 7.4$ & $58.0 \pm 8.1$ & $<.001$ \\
\hline $\mathrm{PASP}>50 \mathrm{~mm} \mathrm{Hg}$ & $82(13.0)$ & $39(10.0)$ & $43(17.8)$ & .005 \\
\hline $\mathrm{AF}$ & $124(19.6)$ & $58(14.9)$ & $66(27.3)$ & $<.001$ \\
\hline
\end{tabular}

Data presented as mean \pm standard deviation or n (\%). $L V$, Left ventricular; $L V E F$, left ventricular ejection fraction; $L V E S D$, left ventricular end-systolic diameter; $P A$, pulmonary artery; $L V E D D$, left ventricular end-diastolic diameter; $P A S P$, pulmonary artery systolic pressure; $A F$, atrial fibrillation.

developed postoperative LV dysfunction. When the preoperative LVEF was $<60 \%$, the LVESD was $>40 \mathrm{~mm}$, and $\mathrm{AF}$ and PHT were present, the incidence of postoperative LV dysfunction increased to $66.7 \%$ (Table 5).

We examined the mortality and morbidity between the 2 groups (Table 6). One patient in the entire series died $(0.2 \%)$ but that patient had not developed postoperative LV dysfunction. When comparing major postoperative morbidity, we found no significant differences between the 2 groups. The incidence of major morbidity and/or mortality was $5.7 \%$. Respiratory failure, defined as mechanical ventilation for $>48$ hours (for any reason), occurred in $4 \%$ of patients without LV dysfunction and
$3.6 \%$ of patients with LV dysfunction $(P=.549)$. The cause in most of these cases was related to postoperative right ventricular dysfunction in those with longer crossclamp times, and the patients required inotropic support for the right ventricle.

\section{DISCUSSION}

Postoperative LV dysfunction after mitral valve surgery has been shown to occur in a number of studies. ${ }^{2,7}$ Similar to these series, the incidence of postoperative LV dysfunction after mitral valve repair in our series was significant, despite $85.3 \%$ of our patients having a preoperative LVEF of $>50 \%$. Understanding the

TABLE 2. Operative data

\begin{tabular}{|c|c|c|c|c|}
\hline \multirow[b]{2}{*}{ Variable } & \multirow[b]{2}{*}{ All patients $(n=632)$} & \multicolumn{3}{|c|}{ Postoperative LV dysfunction } \\
\hline & & No $(n=390)$ & Yes $(n=242)$ & $P$ value \\
\hline Crossclamp time (min) & $131 \pm 48$ & $132 \pm 46$ & $130 \pm 52$ & .848 \\
\hline Cardiopulmonary bypass time (min) & $167 \pm 77$ & $162 \pm 51$ & $176 \pm 111$ & .269 \\
\hline Barlow's disease & $339(53.6)$ & $206(52.8)$ & $133(55.0)$ & .600 \\
\hline Anterior leaflet prolapse & $27(4.3)$ & $18(4.6)$ & $9(3.7)$ & .588 \\
\hline Posterior leaflet prolapse & $475(75.2)$ & $289(74.1)$ & $186(76.9)$ & .436 \\
\hline Bileaflet prolapse & $123(19.5)$ & $78(20.0)$ & 45 (18.6) & .665 \\
\hline Concomitant CABG & $58(9.2)$ & $30(7.7)$ & $28(11.6)$ & .101 \\
\hline Concomitant TVR & $413(65.3)$ & $249(63.8)$ & $164(67.8)$ & .314 \\
\hline Concomitant maze procedure & $123(19.5)$ & $58(14.9)$ & $65(26.9)$ & $<.001$ \\
\hline
\end{tabular}

Data presented as mean \pm standard deviation or $\mathrm{n}(\%) . L V$, Left ventricular; $C A B G$, coronary artery bypass grafting; $T V R$, tricuspid valve repair. 


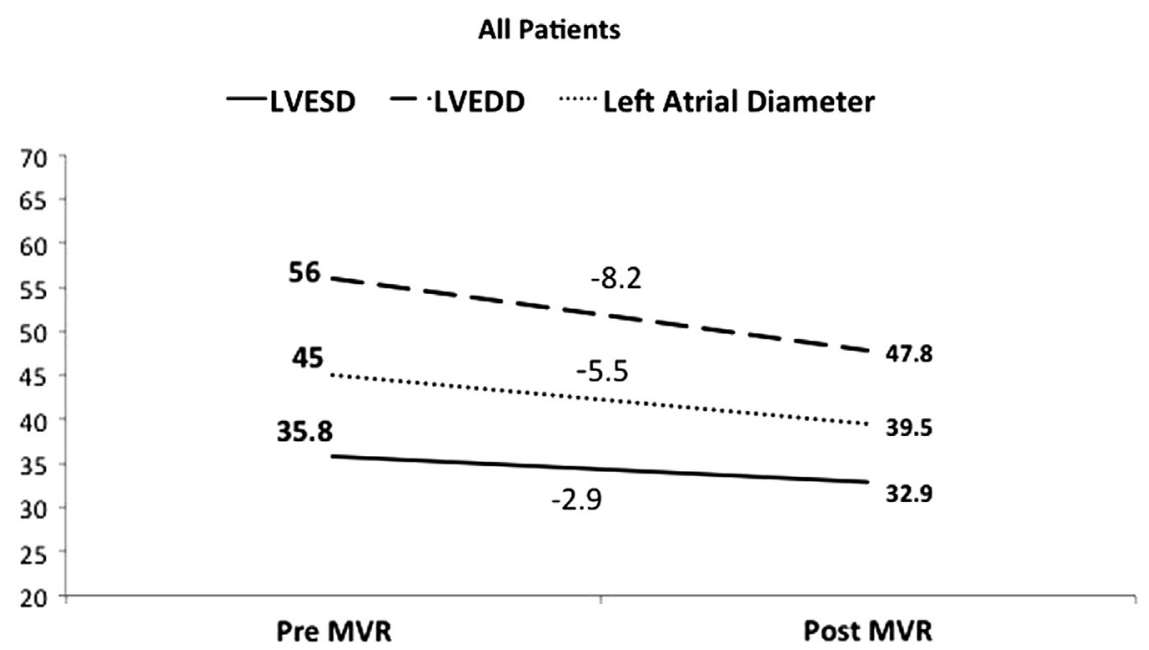

FIGURE 1. The preoperative and postoperative cardiac chamber sizes for all patients. $L V E S D$, Left ventricular end-systolic diameter; $L V E D D$, left ventricular end-diastolic diameter; $M V R$, mitral valve repair.

predictive factors provides insight into the postoperative treatment of patients with degenerative mitral valve disease. In our study, the LVESD and the presence of PHT and AF independently predicted postoperative LV dysfunction (LVEF $<50 \%$ ). In a series of 861 patients, Suri and colleagues ${ }^{2}$ examined the predictors of LV dysfunction after mitral valve surgery and also found that increased LV size, worsening heart failure symptoms, preoperative LVEF, and AF predicted postoperative LV dysfunction. Their series consisted of a mixed population of patients undergoing either valve repair or replacement. Tribouilloy and colleagues ${ }^{7}$ examined the predictors of LV dysfunction at 10.8 months after mitral valve repair. At 10 months after surgery, they continued to find a decrease in the mean LVEF of $9 \%$. The largest incidence of postoperative LV dysfunction (33\%) was found in those patients with a preoperative LVEF $<64 \%$ and LVESD $\geq 37 \mathrm{~mm}$. Our study is unique in that it examined early postoperative LV dysfunction (mean, 4.1 days) in patients who had only undergone mitral valve repair for degenerative disease.

TABLE 3. Predictors of postoperative left ventricular ejection fraction (continuous variables)

\begin{tabular}{lrrrrc}
\hline & \multicolumn{2}{c}{ Univariate } & & \multicolumn{2}{c}{ Multivariate } \\
\cline { 2 - 3 } \cline { 6 - 7 } \multicolumn{1}{c}{ Variable } & \multicolumn{1}{c}{$\boldsymbol{\beta}$} & $\boldsymbol{P}$ value & & $\boldsymbol{\beta}$ & $\boldsymbol{P}$ value \\
\hline Age $(\mathrm{y})$ & -0.092 & .021 & & - & .793 \\
LVEF $(\%)$ & 0.209 & $<.001$ & & 0.076 & .057 \\
ESD $(\mathrm{mm})$ & -0.337 & $<.001$ & & -0.299 & $<.001$ \\
PASP (mm Hg) & -0.205 & $<.001$ & & -0.167 & $<.001$ \\
Left atrial diameter (mm) & -0.185 & $<.001$ & & - & $.407 *$ \\
Crossclamp time (min) & -0.006 & .652 & & - & - \\
\hline
\end{tabular}

$\overline{L V E F}$, Left ventricular ejection fraction; ESD, end-systolic diameter; PASP, pulmonary artery systolic pressure. *Multivariate analysis using left atrial diameter was performed separately because of a larger number of missing cases.
Our study did not find that the preoperative LVEF predicted postoperative $\mathrm{LV}$ dysfunction, in contrast to previous published studies. On multivariate analysis, the $P$ value for this measurement was .057. Although it showed a trend toward significance, the preoperative LVEFs were very similar in both groups and, hence, led to a type 1 error in our study, because we did not have a sufficient sample size to elicit a difference between the 2 groups.

We observed an overall decrease in the LVEF of $7.2 \%$ postoperatively. A number of explanations exist for this decrease in the postoperative LVEF. Starling and colleagues $^{8}$ illustrated that the LVEF in the presence of mitral regurgitation is overestimated as a result of the increased ventricular preload (end-diastolic volume). After valve repair, this excess preload is removed, leading to a decrease in the end-diastolic volume and, subsequently, a decrease in the LVEF. They showed that the contractile reserve is a better indicator of LV function in the presence of severe mitral regurgitation. Their work has been

TABLE 4. Predictors of postoperative left ventricular dysfunction (categorical variables)

\begin{tabular}{|c|c|c|c|c|}
\hline \multirow[b]{2}{*}{ Variable } & \multicolumn{2}{|c|}{ Univariate } & \multicolumn{2}{|c|}{ Multivariate } \\
\hline & OR $(95 \%$ CI $)$ & $\begin{array}{c}P \\
\text { value }\end{array}$ & OR $(95 \%$ CI $)$ & $\begin{array}{c}P \\
\text { value }\end{array}$ \\
\hline Age (y) & $1.02(1.00-1.03)$ & .014 & & .667 \\
\hline Female gender & $0.82(0.59-1.15)$ & .255 & & - \\
\hline Symptomatic & $0.94(0.68-1.30)$ & .722 & & - \\
\hline History of AF & $2.49(1.66-3.75)$ & $<.001$ & $1.97(1.28-3.02)$ & .002 \\
\hline PASP > $50 \mathrm{~mm} \mathrm{Hg}$ & $1.95(1.22-3.10)$ & .005 & $1.82(1.11-2.97)$ & .017 \\
\hline Concomitant CABG & $1.57(0.91-2.70)$ & .103 & & .176 \\
\hline Concomitant TVR & $1.19(0.85-1.67)$ & .314 & & - \\
\hline
\end{tabular}

In the final model, Hosmer-Lemeshow $=0.814$; c-statistic $=0.680 . O R$, Odds ratio; $C I$, confidence interval; $A F$, atrial fibrillation; $P A S P$, pulmonary artery systolic pressure; $C A B G$, coronary artery bypass grafting; $T V R$, tricuspid valve repair. 
TABLE 5. Prevalence of postoperative $L V$ dysfunction according to presence of preoperative guideline parameters

\begin{tabular}{lc}
\hline \multicolumn{1}{c}{ Preoperative guideline parameters } & $\begin{array}{c}\text { Postoperative LV } \\
\text { dysfunction (n) }\end{array}$ \\
\hline $\mathrm{LVEF}<60 \%$ only & $26 / 76(34.2)$ \\
$\mathrm{LVEF}<60 \%+\mathrm{ESD}>40 \mathrm{~mm}$ & $26 / 54(48.1)$ \\
$\mathrm{LVEF}<60 \%+\mathrm{ESD}>40 \mathrm{~mm}+\mathrm{AF}$ or PHT & $17 / 24(70.8)$ \\
$\mathrm{LVEF}<60 \%+\mathrm{ESD}>40 \mathrm{~mm}+\mathrm{AF}+\mathrm{PHT}$ & $4 / 6(66.7)$ \\
\hline Data in parentheses are percentages. $P=.010$ for all. $L V$, Left ventricular; \\
$L V E F$, left ventricular ejection fraction; ESD, end-systolic diameter; $A F$, atrial \\
fibrillation; $P H T$, pulmonary hypertension.
\end{tabular}

supported by more recent evidence that measurements other than the LVEF, such global strain and speckle tracking, can better assess ventricular function when severe mitral regurgitation is present. ${ }^{9,10}$ Other arguments for the early decrease in the LVEF could be the increased afterload in the ventricle after valve repair and the stress and/or myocardial injury that occurs after aortic crossclamping. A recent study found a similar decrease in the LVEF, in addition to global longitudinal and circumferential strain, on early postoperative echocardiograms at 7 days. ${ }^{11}$

Our finding that preoperative PHT increased the incidence of postoperative LV dysfunction was likely a result of the severity and duration of mitral regurgitation. Enriquez-Sarano and colleagues ${ }^{12}$ elegantly reported that as the severity of mitral regurgitation increased, a corresponding increase occurred in the pulmonary artery pressures. PHT also increased the incidence of right ventricular dysfunction and could subsequently lead to a decrease in LV preload and LVEF. In a recent multicenter registry, patients with PHT had an increased risk of operative mortality (hazard ratio, $2.15 ; P=.01$ ) after mitral valve surgery. ${ }^{13}$ Furthermore, long-term survival was also diminished in the same study.

Just as with PHT, AF is a marker of the severity of regurgitation and portends a worse prognosis in patients

TABLE 6. Perioperative mortality and morbidity

\begin{tabular}{lcccc}
\hline & & \multicolumn{3}{c}{ Postoperative LV dysfunction } \\
\cline { 3 - 5 } \multicolumn{1}{c}{ Variable } & $\begin{array}{c}\text { All patients } \\
(\mathbf{n}=\mathbf{6 3 2})\end{array}$ & $\begin{array}{c}\text { No } \\
(\mathbf{n}=\mathbf{3 9 0})\end{array}$ & $\begin{array}{c}\text { Yes } \\
(\mathbf{n}=\mathbf{2 4 2})\end{array}$ & $\begin{array}{c}\boldsymbol{P} \\
\text { value }\end{array}$ \\
\hline 30-d Mortality & $1(0.2)$ & $1(0.3)$ & $0(0)$ & 1.000 \\
Mortality and morbidity & $36(5.7)$ & $22(5.6)$ & $14(5.8)$ & .939 \\
Stroke & $9(1.4)$ & $6(1.5)$ & $3(1.2)$ & .758 \\
Myocardial infarction & 0 & 0 & 0 & \\
Sternal wound infection & $5(0.8)$ & $4(1.0)$ & $1(0.4)$ & .654 \\
Bleeding & $4(0.6)$ & $1(0.3)$ & $3(1.2)$ & .159 \\
Sepsis & $7(1.1)$ & $2(0.5)$ & $5(2.1)$ & .113 \\
Gastrointestinal bleeding & $1(0.2)$ & $1(0.3)$ & $0(0)$ & 1.000 \\
Renal failure & $3(0.5)$ & $2(0.5)$ & $1(0.4)$ & 1.000 \\
Respiratory failure & $25(4.0)$ & $14(3.6)$ & $11(4.5)$ & .549 \\
Reoperation & $5(0.8)$ & $3(0.8)$ & $2(0.8)$ & 1.000 \\
\hline Dat pres & & & &
\end{tabular}

Data presented as n (\%). $L V$, Left ventricular. with severe mitral regurgitation. ${ }^{14} \mathrm{AF}$ has also been shown to predict late survival after mitral valve repair. ${ }^{15}$ The greatest incidence of postoperative LV dysfunction was seen when patients presented with a combination of LV dysfunction, increased ventricular dimensions, PHT, and AF.

Postoperative LV dysfunction did not affect mortality or morbidity after valve repair. We believe this was because our threshold for defining LV dysfunction was $50 \%$, and most patients who developed LV dysfunction still had a postoperative mean LVEF just $<50 \%$. One could postulate that if the threshold definition of $\mathrm{LV}$ dysfunction was moved toward $35 \%$ to $40 \%$, a greater incidence of postoperative complications would likely be seen, given the potential for a longer intensive care unit and hospital stay; however, this was not examined in our study.

In the present study, the presence of symptoms did not increase the incidence of postoperative LV dysfunction. However, given the finding of a twofold increase in the risk of postoperative dysfunction in patients with preoperative AF or PHT, these results support close follow-up with a low threshold for surgical intervention for patients with severe degenerative mitral valve disease. We also believe that, in expert centers, early surgery in asymptomatic patients should be considered where mortality and morbidity remain low.

The strengths of the present study were the large sample size and a homogenous population of patients with only degenerative mitral valve disease. In addition, all patients in the present series underwent valve repair. The limitations of our study were its retrospective data collection. The preoperative echocardiograms were frequently performed at outside institutions; thus, an operator bias exists in the interpretation of the echocardiograms. Finally, the lasting implications of early postoperative ventricular dysfunction were not examined.

\section{CONCLUSIONS}

Early postoperative LV dysfunction occurs commonly after mitral valve repair for degenerative disease. The independent predictors of postoperative LV dysfunction were a large LV chamber size, PHT, and AF. Although no increase in perioperative mortality or morbidity was observed, patients who present with preoperative AF or PHT had a twofold increase risk of developing postoperative LV dysfunction.

\footnotetext{
References

1. Zile MR, Gaasch WH, Carroll JD, Levine HJ. Chronic mitral regurgitation: predictive value of preoperative echocardiographic indexes of left ventricular function and wall stress. J Am Coll Cardiol. 1984;3(2 Pt 1):235-42.

2. Suri RM, Schaff HV, Dearani JA, Sundt TM, Daly RC, Mullany CJ, et al. Determinants of early decline in ejection fraction after surgical correction of mitral regurgitation. J Thorac Cardiovasc Surg. 2008;136:442-7.

3. Enriquez-Sarano M, Tajik AJ, Schaff HV, Orszulak TA, McGoon MD, Bailey KR, et al. Echocardiographic prediction of left ventricular function after
} 
correction of mitral regurgitation: results and clinical implications. J Am Coll Cardiol. 1994;24:1536-43.

4. Matsumura T, Ohtaki E, Tanaka K, Misu K, Tobaru T, Asano R, et al. Echocardiographic prediction of left ventricular dysfunction after mitral valve repair for mitral regurgitation as an indicator to decide the optimal timing of repair. J Am Coll Cardiol. 2003;42:458-63.

5. Castillo JG, Anyanwu AC, Fuster V, Adams DH. A near 100\% repair rate for mitral valve prolapse is achievable in a reference center: implications for future guidelines. J Thorac Cardiovasc Surg. 2012;144:308-12.

6. Varghese RADH. Techniques for repairing posterior leaflet prolapse of the mitral valve. Oper Tech Thorac Cardiovasc Surg. 2011;16:293-308.

7. Tribouilloy C, Rusinaru D, Szymanski C, Mezghani S, Fournier A, Levy F, et al. Predicting left ventricular dysfunction after valve repair for mitral regurgitation due to leaflet prolapse: additive value of left ventricular end-systolic dimension to ejection fraction. Eur J Echocardiogr. 2011;12: 702-10.

8. Starling MR, Kirsh MM, Montgomery DG, Gross MD. Impaired left ventricular contractile function in patients with long-term mitral regurgitation and normal ejection fraction. J Am Coll Cardiol. 1993;22:239-50.

9. Lancellotti P, Cosyns B, Zacharakis D, Attena E, Van Camp G, Gach O, et al. Importance of left ventricular longitudinal function and functional reserve in patients with degenerative mitral regurgitation: assessment by twodimensional speckle tracking. J Am Soc Echocardiogr. 2008;21:1331-6.

10. Witkowski TG, Thomas JD, Debonnaire PJ, Delgado V, Hoke U, Ewe SH, et al. Global longitudinal strain predicts left ventricular dysfunction after mitral valve repair. Eur Heart J Cardiovasc Imaging. 2013;14:69-76.

11. Witkowski TG, Thomas JD, Delgado V, van Rijnsoever E, Ng AC, Hoke U, et al. Changes in left ventricular function after mitral valve repair for severe organic mitral regurgitation. Ann Thorac Surg. 2012;93:754-60.

12. Enriquez-Sarano M, Avierinos JF, Messika-Zeitoun D, Detaint D, Capps M, Nkomo V, et al. Quantitative determinants of the outcome of asymptomatic mitral regurgitation. N Engl J Med. 2005;352:875-83.

13. Barbieri A, Bursi F, Grigioni F, Tribouilloy C, Avierinos JF, Michelena HI, et al Prognostic and therapeutic implications of pulmonary hypertension complicating degenerative mitral regurgitation due to flail leaflet: a multicenter long-term international study. Eur Heart J. 2011;32:751-9.

14. Grigioni F, Avierinos JF, Ling LH, Scott CG, Bailey KR, Tajik AJ, et al Atrial fibrillation complicating the course of degenerative mitral regurgitation: determinants and long-term outcome. J Am Coll Cardiol. 2002;40:84-92.

15. Enriquez-Sarano M, Tajik AJ, Schaff HV, Orszulak TA, Bailey KR, Frye RL. Echocardiographic prediction of survival after surgical correction of organic mitral regurgitation. Circulation. 1994;90:830-7. 